\title{
TITLE:
}

\section{$<$ Note $>$ Sharing of Wild Fruits among Male Chimpanzees: Two Cases from Mahale, Tanzania}

\section{AUTHOR(S):}

Nakamura, Michio; Itoh, Noriko

\section{CITATION:}

Nakamura, Michio ...[et al]. < Note> Sharing of Wild Fruits among Male

Chimpanzees: Two Cases from Mahale, Tanzania. Pan Africa News 2001, $8(2): 28-31$

\section{ISSUE DATE:}

2001-12

URL:

http://hdl.handle.net/2433/143398

\section{RIGHT:}

Copyright (C) Pan Africa News. 
<NOTE>

Sharing of Wild Fruits among Male Chimpanzees: Two Cases from Mahale, Tanzania

\author{
Michio Nakamura \\ Japan Monkey Centre \\ and Noriko Itoh
}

Graduate School of Science, Kyoto University

\title{
Introduction
}

Food-sharing is deeply related with important events in human evolution, such as the evolution of the family, bipedalism, cooperative hunting (e.g. 2), circulating economy and empathy (3), natural institutions (4), and communication leading to language (5). Genus Pan, though not to the extent of humans, is one of the primate taxon where food-sharing is commonly observed. Most reports on the food-sharing of chimpanzees concern meat (9) and provisioned food (6). Although bilias (pygmy chimpanzees) are well known to share wild plant foods among adults (4), sharing is generally between mothers and dependent offspring (7), and there have been few. reports on it (e.g. 9) among adults in chimpanzees. We report two cases of natural plant food sharing among the mature chimpanzees of the Mahale $M$ group.

Case 1: Sharing of lemon fruit.

An event that occurred on September 28, 1997 is summarized in Fig. 1. The lemon fruit was introduced in Mahale by humans, so it is not a wild species in the strict sense. However, it has gone wild and since 1982 (8) has been regularly eaten by $\mathrm{M}$ group members. Lemon trees usually bear a large amount of fruit, and there was plenty of fruit in the nearby trees in this case. The process of lemon fruit sharing is illustrated in Fig. 1.

After this event, $\mathrm{AL}$ took two lemons himself and began to eat on the ground when $\mathrm{BB}$ finished his last quarter. BB moved a bit and peered at AL's lemon, but AL slowly turned his back. While $B B$ was still peering, a female Ako. (AK, in estrus) approached. As she came close, $\mathrm{BB}$ made room for her and AK lay down there. 

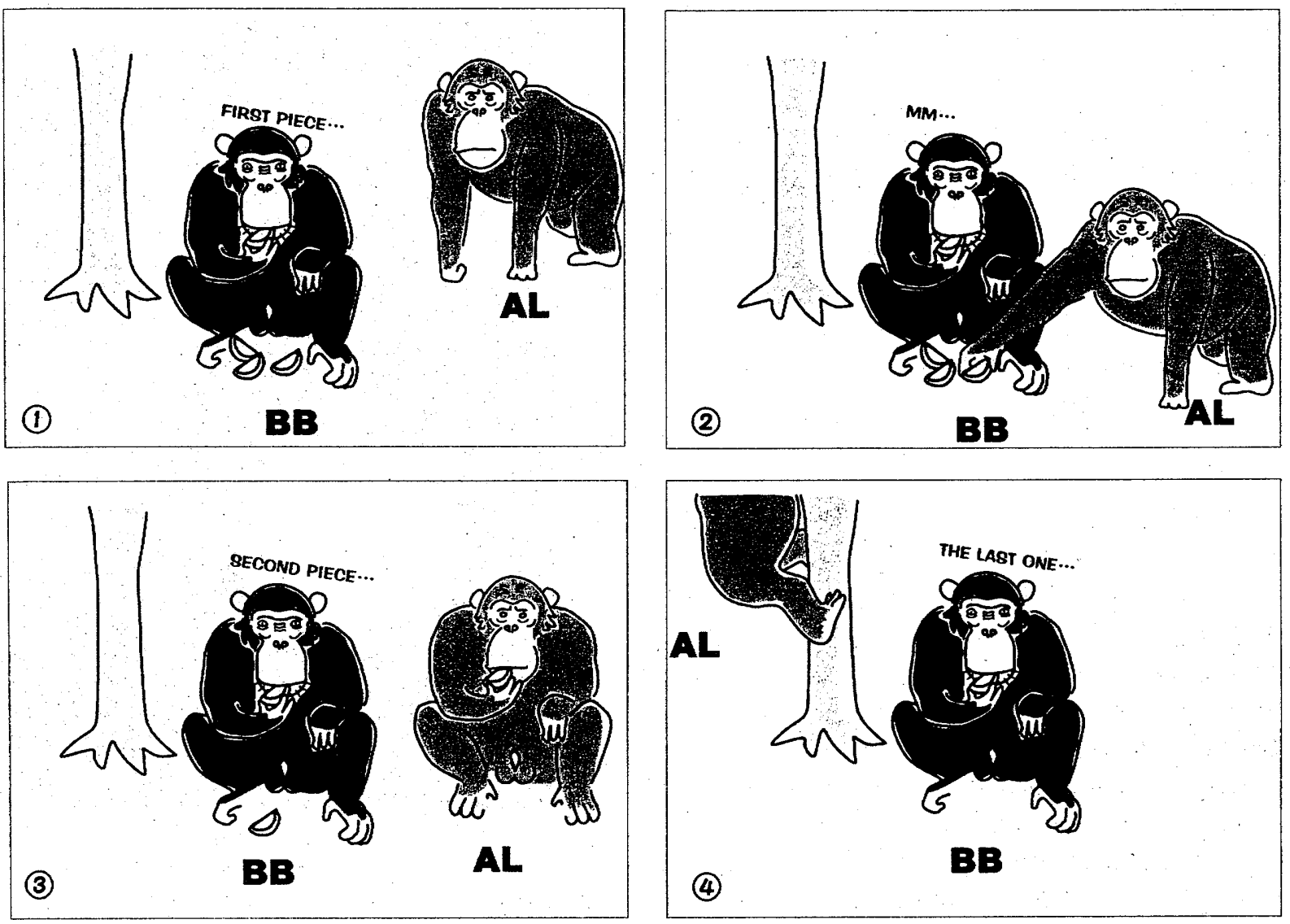

Figure 1.(1) An adolescent male Bonobo (BB 15 yrs) eating a quarter of lemon fruit, leaving the remaining three quarters on the ground between his feet when another adolescent male Alofu (AL 15 yrs) arrives.

(2) AL picking up one of the quarters from $\mathrm{BB}$ without even begging.

(3) $\mathrm{AL}$ eating the lemon quarter near $\mathrm{BB}$. BB not showing any reaction but instead continuing to eat the second quarter.

(4) After finishing the quarter, AL climbing a lemon tree nearby to look for some fruit.

AL was still eating his half of the first lemon, putting the other half on the ground between his feet and holding the second fruit with his foot. AK slowly took AL's lemon on the ground and started to eat. Subsequently, AL put the second one on the ground between his feet, but neither $\mathrm{AK}$ nor $\mathrm{BB}$ tried to reach for it.

Case 2: Sharing of Voacanga africana fruit pulp. On August 18, 2000, focal adult male Dogura (DG $19 \mathrm{yrs})$ was found at $14: 19$, when he was peering at the meat consumption by other individuals. Subsequently, DG set off, obtaining no meat. Then, DG checked some Voacanga africana fruit by sniffing and biting, but could not find a ripe one. The fruit of Voacanga (Fig. 2) is one of the largest fruits in Mahale, about $1 \mathrm{~kg}$ in weight and $15 \mathrm{~cm}$ in diameter. However, the edible part, the juicy pulp around the seeds, is only $5 \mathrm{~cm}$ in diameter. The availability of Voacanga fruit is not very high, since chimpanzees selectively eat the ripe ones. Thus, it is not very common for them to eat it, but they seem to prefer it because they occasionally check this fruit as DG did.

At 14:41, DG came to lower ranking male Masudi (MA 22 yrs) who was chewing a mouthful of Voacanga pulp. Judging from the amount of pulp, MA must have obtained at least five or more pieces of fruit. DG began begging by extending his arm to MA's mouth. DG obtained some pulp from MA's mouth (Fig. 3). MA moved several meters and lay on his back, still sometimes putting the wadge in and out of his mouth. DG sat by MA and extended his hand to MA's mouth 26 times for a total duration of 2.3 min during 4.4 minutes of video observation, sometimes putting his index finger slightly into MA's mouth. He was successful in obtaining pulp 
15 times.

Although DG was dominant over MA, he seemed to be a bit tense, sitting straight and self-scratching roughly 7 times and self-grooming once during the course. On the other hand, MA looked quite relaxed, lying on his back and self-scratching once only slightly. MA sometimes cast glances at DG, which seemed to be related to his manipulation of the wadge. DW was sitting about 1-2 $\mathrm{m}$ from $\mathrm{DG}$ and $\mathrm{MA}$, but never joined in this series of interactions.

\section{Discussion}

It is difficult to make any generalization from these two cases. There were differences in the sizes of the fruits, the ways of begging and sharing, the activeness of the sharer, or the availability of the fruits. However there are also common features, such as both interactions being dyadic without vocalization or aggression. Such characteristics of interaction are more similar to that between mother and infant, where the latter's taking food from the former can be tolerated, than that between individuals in meat sharing (9). It is noteworthy that adult males, who are more aggressive than individuals of any other age/sex class, can show such a high degree of tolerance as that between mother and offspring in some cases.

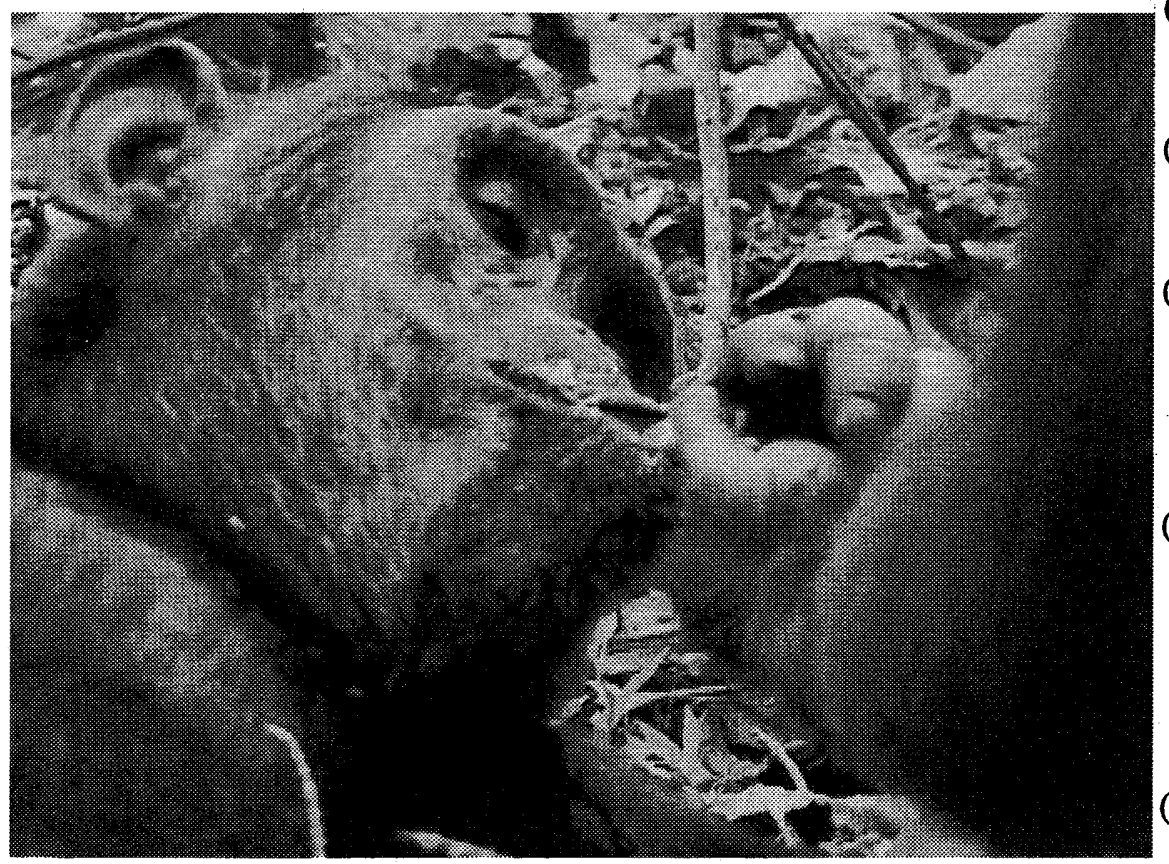

Figure 3. DG (right) obtaining pulp from MA's (left) mouth.

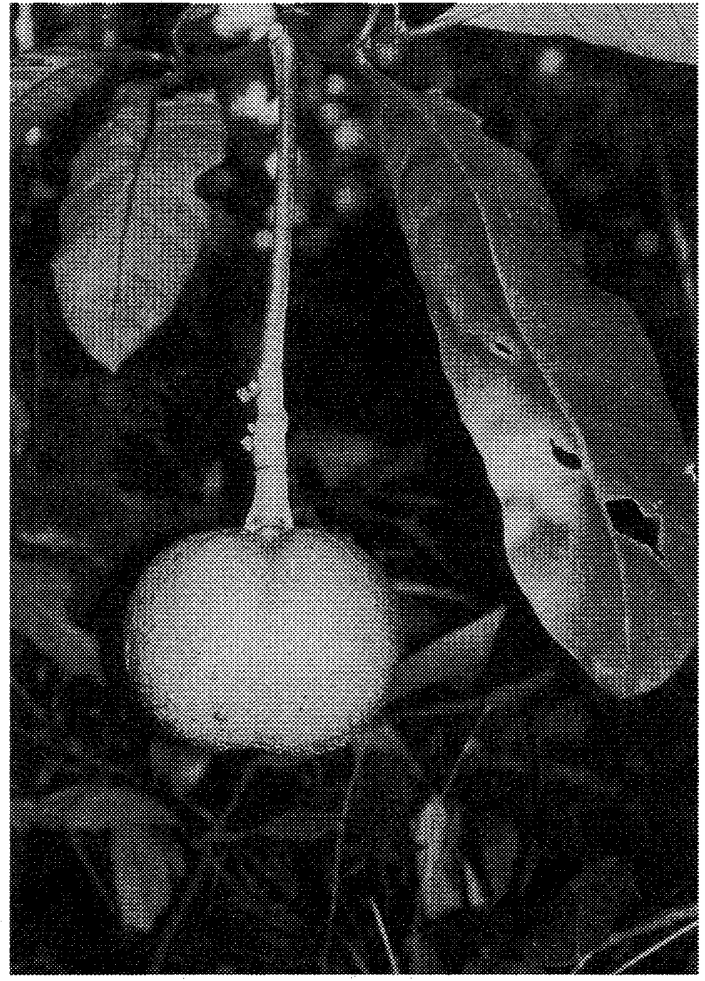

Figure 2. A Voacanga africana fruit.

\section{References}

(1) Boesch C, Boesch H 1984. Possible causes of sex differences in the use of natural hammers by wild chimpanzees. J. Hum. Evol. 13: 415-440.

(2) Issac G 1978. The food-sharing behavior of protohuman hominids. Sci. Amer. 238: 90-108.

(3) Itani $J$ 1978. Evolution of Primate Society, Heibonsha, Tokyo.

(4) Kuroda S 1999. Reconsidering Human Evolution, Ibunsha, Tokyo.

(5) Kitamura K 1999. "Origin of language" from the view of communication. Hirosaki Univ. Jinbun-Shakai Ronsou. 2:45-70.

(6) McGrew WC 1975. Patterns of plant food sharing by wild chimpanzees. In: Kondo $\mathrm{S}$, Kawai M, Ehara A (eds.), Contemporary Primatology, Basel Karger, pp. 304-309.

(7) Nishida T, Turner LA 1996. Food transfer between mother and infant chimpanzees of 
Mahale Mountains National Park, Tanzania. Int. J. Primatol. 17: 947-968.

(8) Takahata Y, Hiraiwa-Hasegawa M, Takasaki $\mathrm{H}$, Nyundo R 1986. Newly acquired feeding habits among the chimpanzees of the Mahale Mountains National Park, Tanzania. Hum. Evol. 1: 277-284

(9) Wrangham RW 1975. The Behavioural Ecology of Chimpanzees in Gombe National Park, Tanzania. PhD thesis, University of Cambridge. 